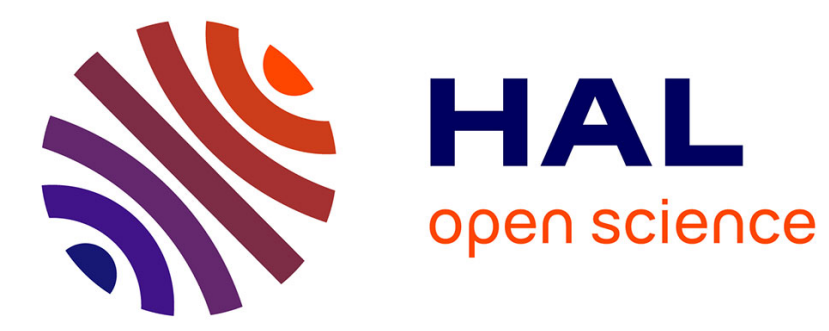

\title{
Role of surface hydroxylation on adhesion at zinc/silica interfaces
}

\author{
Ha-Linh Thi Le, Jacek Goniakowski, Claudine Noguera, Alexey Koltsov, \\ Jean-Michel Mataigne
}

\section{- To cite this version:}

Ha-Linh Thi Le, Jacek Goniakowski, Claudine Noguera, Alexey Koltsov, Jean-Michel Mataigne. Role of surface hydroxylation on adhesion at zinc/silica interfaces. Physical Chemistry Chemical Physics, 2018, 20 (22), pp.15581 - 15588. 10.1039/C8CP02139B . hal-01911235

\section{HAL Id: hal-01911235 \\ https://hal.sorbonne-universite.fr/hal-01911235}

Submitted on 29 Jan 2020

HAL is a multi-disciplinary open access archive for the deposit and dissemination of scientific research documents, whether they are published or not. The documents may come from teaching and research institutions in France or abroad, or from public or private research centers.
L'archive ouverte pluridisciplinaire $\mathbf{H A L}$, est destinée au dépôt et à la diffusion de documents scientifiques de niveau recherche, publiés ou non, émanant des établissements d'enseignement et de recherche français ou étrangers, des laboratoires publics ou privés. 


\title{
Journal Name
}

\section{ARTICLE TYPE}

Cite this: DOI: $10.1039 / \operatorname{xxxxxxxxxx}$

\section{Role of surface hydroxylation on adhesion at zinc/silica interfaces.}

\author{
Ha-Linh Thi Le, ${ }^{a b c}$ Jacek Goniakowski, ${ }^{* a b}$ Claudine Noguera, ${ }^{a b}$ Alexey Koltsov, ${ }^{c}$ and \\ Jean-Michel Mataigne ${ }^{c}$
}

Received Date

Accepted Date

DOI: $10.1039 / x x x x x x x x x x$

www.rsc.org/journalname
The weak interaction between zinc and silica is responsible for a poor performance of anticorrosive galvanic zinc coatings on modern advanced high strength steels which are fundamental in the automotive industry, and important for rail transport, shipbuilding, or aerospace. With the goal of identifying possible levers for its improvement, we report an ab initio study of the effect of surface hydroxylation on the adhesion characteristics of model zinc/ $\beta$-cristobalite interfaces, representative for various surface hydroxylation/hydrogenation conditions. We show that surface silanols resulting from dissociative water adsorption at the most stable stoichiometric (001) and (111) surfaces prevent strong zinc-silica interaction. However, dehydrogenation of such interfaces produces oxygen-rich zinc/silica contacts with excellent adhesion characteristics. They are due to a partial zinc oxidation and the formation of strong iono-covalent $\mathrm{Zn}-\mathrm{O}$ bonds between zinc atoms and the under-coordinated excess anions, remnant of the hydroxylation layer. Interestingly, these interfaces appear as the most thermodynamically stable in a wide range of realistic oxygen-rich and hydrogen-lean environments. We also point out that the partial oxidation of zinc atoms in direct contact with the oxide substrate may somewhat weaken the cohesion in the zinc deposit itself. This fundamental analysis of the microscopic mechanisms responsible for the improved zinc wetting on pre-hydroxylated silica substrates furnishes useful guidelines towards practical attempts to improve adhesion.

\section{Introduction}

Galvanic zinc protection of iron-based materials has long proved its efficiency since zinc sacrificially corrodes to protect steel. ${ }^{1}$ However, with the advent of advanced high strength steels (AHSS), ${ }^{2-7}$ the optimization of anti-corrosive galvanic zinc coatings faces new challenges. Indeed, the recrystallization annealing of AHSS strips in a reducing atmosphere provokes a selective oxidation of light strengthening elements ( $\mathrm{Al}, \mathrm{Si}$, and $\mathrm{Mn}$ ) and the segregation of their oxides to the steel surfaces, which dramatically reduces the zinc adhesion. ${ }^{8,9}$ In particular, the recrystallization annealing of Si-alloyed steels may lead to the formation of a quasi-continuous amorphous silica film on the steel top surface. ${ }^{9}$ With the introduction of the new industrial process of Jet Vapor Deposition (JVD) of zinc under vacuum ${ }^{10,11}$, a much better control of the industrial zinc/steel interface becomes possible. An assessment of zinc/silica interactions under different thermody-

\footnotetext{
a CNRS, UMR 7588, Institut des Nanosciences de Paris, F-75005 Paris, France. E-mail: jacek.goniakowski@insp.jussieu.fr

${ }^{b}$ Sorbonne Université, Institut des Nanosciences de Paris, UMR 7588, INSP, F-75005 Paris, France.

${ }^{c}$ ArcelorMittal Maizières Research, voie Romaine, F-57280, Maizières lès Metz, France.
}

namic conditions will help to obtain a more precise understanding of the microscopic mechanisms responsible for the interfacial strength and to define appropriate process parameters promoting the adhesion of zinc coating on Si-alloyed grades.

While many theoretical studies have been dedicated to the adhesion of transition and noble metals on various wide-gap oxide surfaces, ${ }^{12-16}$ the same is not necessarily true for silica. Taking into account the limited use of large size simulation models, ${ }^{17-20}$ the strategy often adopted in the past consists of mimicking amorphous silica surfaces by those of one of its crystalline polymorphs. Within this strategy, beyond the existing studies on $\mathrm{Cu}$ or $\mathrm{Ag}$ in contact with cristobalite, ${ }^{21,22}$ and $\mathrm{Ni}, \mathrm{Al}, \mathrm{Ag}$, or Pt interacting with quartz, ${ }^{23-26}$ we have recently analyzed zinc/ $\beta$-cristobalite interfaces. ${ }^{27}$. We have shown that the most stable stoichiometric terminations expose two-member Si-O rings, which have also been identified in models of dehydroxylated amorphous silica. ${ }^{20}$ According to our results, the interaction of zinc with intact surface siloxanes is very weak, but it can be considerably enhanced if the siloxane rings are broken. Surface pre-hydroxylation may be a promising way to achieve this. Moreover, it has been shown that reaction of metal adatoms with surface $\mathrm{OH}$ groups on prehydroxylated alumina results in a formation of strongly bound 
oxidized species, ${ }^{28-32}$ and leads to a substantial improvement of zinc adhesion. ${ }^{33}$.

In the present study, we investigate the effect of silica prehydroxylation on zinc adhesion. To this goal, we rely on the existing $\beta$-cristobalite hydroxylated surface models, ${ }^{27,34-38}$ and focus particularly on (001) and (111) terminations, which expose the two types of experimentally identified surface silanols, namely the single silanols (a single hydroxyl attached to a surface $\mathrm{Si}$ ) and the geminal silanols (two hydroxyls attached to the same surface $\mathrm{Si}$ ). ${ }^{39-41}$ By analyzing the nature and strength of zinc-silica interaction as a function of water, oxygen, and hydrogen thermodynamic conditions we show that, while zinc interaction with hydroxylated surfaces is weak, a significant improvement can be obtained by interface dehydrogenation. We argue that the reinforced interaction is driven by the interface charge transfer and the iono-covalent $\mathrm{Zn}-\mathrm{O}$ bonds formed between the zinc deposit and the under-coordinated excess interfacial anions, remnant of the hydroxylation layer.

The paper is organized as follows. After presenting the details and settings of the computational approach in Sec. 2, in Sec. 3 we (i) briefly describe the hydroxylated surface configurations used in the study, (ii) summarize the results on zinc interaction with fully and partially hydroxylated cristobalite surfaces and (iii) report our findings on the effect of interface dehydrogenation. The results are discussed in Sec. 4.

\section{Computational methods and settings}

All calculations are performed within the Density Functional Theory (DFT) implemented in VASP (Vienna ab initio simulation package). ${ }^{42,43}$ The interaction of valence electrons with ionic cores is described within the projector augmented wave (PAW) method. ${ }^{44,45}$ The Kohn-Sham orbitals are developed on a planewave basis set with a cutoff energy of $400 \mathrm{eV}$ and the selfconsistent iterative solution of the electronic Hamiltonian is pursued until energy differences become less than $10^{-6} \mathrm{eV}$. The dispersion-corrected GGA (optB86-vdW) exchange-correlation functional ${ }^{46-48}$ is used to improve the description of adhesion characteristics, especially at weakly interacting zinc/silica interfaces. Atomic charges are estimated with the partition scheme proposed by Bader, ${ }^{49,50}$ and atomic configurations are plotted with VESTA. ${ }^{51}$

Bulk calculations Following the results and discussion in Ref. ${ }^{52}$, the present study employs the İ̄2d structural variant of the $\beta$ cristobalite. We find that with a $\Gamma$-centered $6 \times 6 \times 6$ MonkhorstPack grid the calculated structural characteristics (lattice parameters, bond lengths, and angles) are converged to within $0.01 \AA$ and $0.01^{\circ}$, respectively, and the formation energies are converged to $0.01 \mathrm{eV} / \mathrm{SiO}_{2}$. In Ref. ${ }^{27}$ we have shown that the calculated and the experimental bulk characteristics are in a good overall agreement.

Surface calculations We consider the most stable stoichiometric (001) and (111) terminations of $\beta$-cristobalite, ${ }^{27}$ which are characterized by different orientations of the surface $\mathrm{SiO}_{4}$ tetrahedra, by a different coordination of surface Si atoms, Fig. 1, and which are terminated by geminal and/or isolated silanol groups upon hydroxylation.

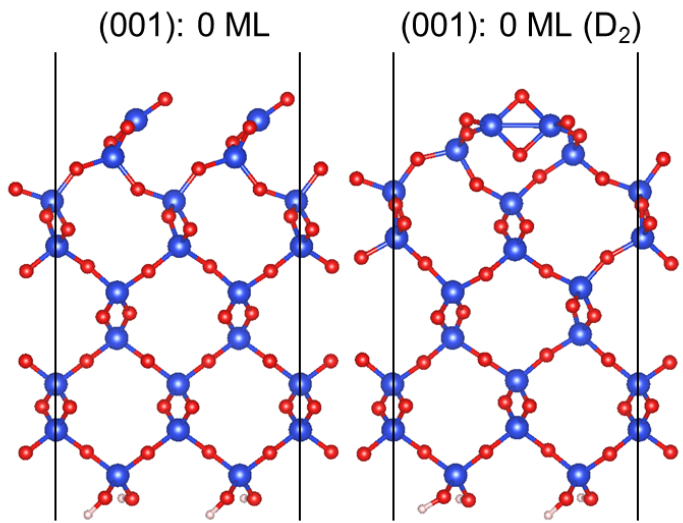

(111): $0 \mathrm{ML}$

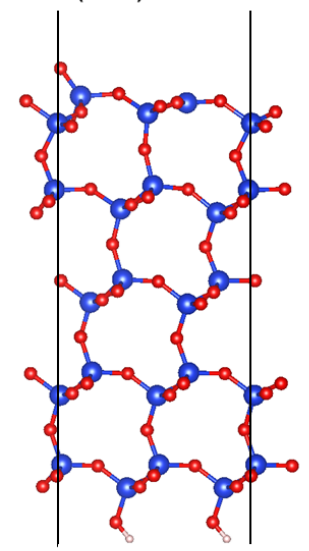

(111): $0 \mathrm{ML}\left(\mathrm{D}_{2}\right)$

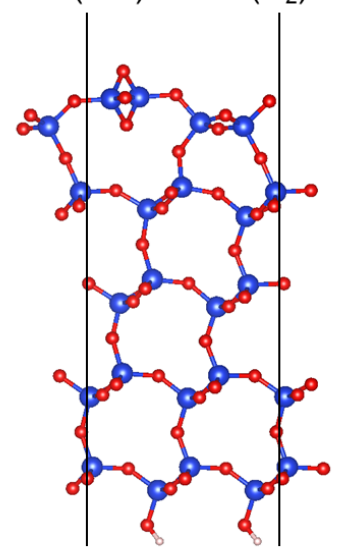

Fig. 1 Relaxed bare stoichimetric (001) (top) and (111) (bottom) surfaces of $\beta$-cristobalite: configurations with broken (left panels) and intact (right panels) surface two-member siloxane rings $\left(D_{2}\right)$. Si, $O$, and $\mathrm{H}$ atoms are represented by large blue, medium red, and small white balls, respectively and surface unit cells used in the calculations are indicated. 
All surfaces are modeled with asymmetric silica slabs, with the top termination used for the study and the fully hydroxylated bottom one ( $N$ water molecules per surface unit cell), separated by at least $10 \AA$ of vacuum. Dipole corrections are used to attenuate the effect of periodic boundary conditions in the direction normal to the slab surfaces. ${ }^{42,53}$ Except for the surface $\mathrm{Si}$ atoms at the bottom termination which are kept fixed, all other atoms are relaxed until forces become smaller than $0.01 \mathrm{eV} \AA^{-1}$. With such settings 9 and $5 \mathrm{SiO}_{2}$ layers, Fig. 1, respectively, are sufficient to converge surface energies of (001) and (111) surfaces to within $0.01 \mathrm{~J} / \mathrm{m}^{2}$.

The total surface energy of the asymmetric slabs is the sum of surface energies of their top $\sigma_{\mathrm{SiO}_{2}\left(\mathrm{H}_{\mathrm{n}} \mathrm{O}_{\mathrm{m}}\right)}$ and their bottom $\sigma_{\mathrm{SiO}_{2}\left(\mathrm{H}_{2} \mathrm{O}\right)_{\mathrm{N}}}$ terminations:

$$
\begin{gathered}
\sigma_{\mathrm{SiO}_{2}\left(\mathrm{H}_{\mathrm{n}} \mathrm{O}_{\mathrm{m}}\right)}+\sigma_{\mathrm{SiO}_{2}\left(\mathrm{H}_{2} \mathrm{O}\right)_{\mathrm{N}}}= \\
\left(\mathrm{E}^{\mathrm{a}-\mathrm{slab}}-\mathrm{E}_{\mathrm{SiO}_{2}}^{\text {bulk }}-\mathrm{n} \mu_{\mathrm{H}}-\mathrm{m} \mu_{\mathrm{O}}-\mathrm{NE}_{\mathrm{H}_{2} \mathrm{O}}\right) / S
\end{gathered}
$$

where $\mathrm{E}^{\mathrm{a}-\text { slab }}, \mathrm{E}_{\mathrm{SiO}_{2}}^{\mathrm{bulk}}$, and $\mathrm{E}_{\mathrm{H}_{2} \mathrm{O}}$ are the total energies of the asymmetric slab, of bulk $\mathrm{SiO}_{2}$, and of a free water molecule, respectively. $\mathrm{n}$ and $\mathrm{m}$ are the numbers of $\mathrm{H}$ and $\mathrm{O}$ atoms adsorbed at the top surface of the slab (per unit cell of area $S$ ), respectively, and $\mu_{H}$ and $\mu_{O}$ are the corresponding chemical potentials. Since the evaluation of $\sigma_{\mathrm{SiO}_{2}\left(\mathrm{H}_{\mathrm{n}} \mathrm{O}_{\mathrm{m}}\right)}$ requires the knowledge of $\sigma_{\mathrm{SiO}_{2}\left(\mathrm{H}_{2} \mathrm{O}\right)_{\mathrm{N}}}=\left(\mathrm{E}^{\mathrm{S}-\mathrm{slab}}-\mathrm{E}_{\mathrm{SiO}_{2}}^{\text {bulk }}-2 \mathrm{NE}_{\mathrm{H}_{2} \mathrm{O}} \mathrm{O} / 2 S\right.$, the total energy $\mathrm{E}^{\mathrm{s}-\text { slab }}$ of a symmetric stoichiometric cristobalite slab with both terminations equivalently hydroxylated with $N$ water molecules each is also calculated.

The composition of the hydroxylation layer is quantified by the numbers of its hydrogen (n) and oxygen (m) atoms (per unit cell) and on their chemical potentials $\mu_{H}$ and $\mu_{O}$. When $n=2 m$, since $2 m \mu_{H}+m \mu_{O}=m \mu_{H_{2} O}$, a reference to the $m$ water molecules is also possible. Each chemical potential $\mu_{\mathrm{X}}$ ( $\mathrm{X}=\mathrm{H}, \mathrm{O}$, and $\mathrm{H}_{2} \mathrm{O}$ ) is conventionally referred to the total energy $\mathrm{E}_{\mathrm{X}}$ of a corresponding free molecule: $\mu_{\mathrm{X}}=\mathrm{E}_{\mathrm{X}} / \mathrm{M}+$ $\Delta \mu_{\mathrm{X}}(M=1$ for water and 2 for di-hydrogen and di-oxygen molecules), such that $\Delta \mu_{\mathrm{X}} \sim 0.0 \mathrm{eV}$ corresponds to the condensation of molecules at the surface. Chemical potential $\mu_{\mathrm{X}}$ can be further explicitly linked to the thermodynamic conditions of the corresponding gas (partial pressure $p_{\mathrm{X}}$ and temperature $T$ ): $\Delta \mu_{\mathrm{X}}\left(\mathrm{T}, \mathrm{p}_{\mathrm{X}}\right)=\Delta \mu_{\mathrm{X}}\left(\mathrm{T}, \mathrm{p}_{0 \mathrm{X}}\right)+1 / 2 \mathrm{k} \operatorname{Tn}\left(\mathrm{p}_{\mathrm{X}} / \mathrm{p}_{0 \mathrm{X}}\right)$.

Interface calculations The simulations of zinc/silica interfaces make use of the above asymmetric slabs with zinc films deposited on the top terminations only. As in Ref. ${ }^{27}$, we have used rectangular $(2 \times 2) \mathrm{Zn}(0001) / /(1 \times 2) \mathrm{SiO}_{2}(001)$ and $(4 \times 2) \mathrm{Zn}(0001) / /(1 \times 1) \mathrm{SiO}_{2}(111)$ coincidence cells, with the inplane lattice parameters fixed to those of bulk silica. We have verified that despite the distortion, the zinc deposits preserve their hexagonal lattice and (0001) orientation and that their surface energies $\sigma_{\mathrm{Zn}}$ are modified by less than $0.2 \mathrm{~J} / \mathrm{m}^{2}$. We have systematically used 9 zinc layers, which assures a convergence of surface and interface energies to within $0.01 \mathrm{~J} / \mathrm{m}^{2}$. In all calculations, the positions of all atoms (except for the surface silicon atoms at the bottom slab termination) are relaxed until residual forces become smaller than $0.01 \mathrm{eV} \AA^{-1}$. The most stable interface configurations are obtained from a series of independent

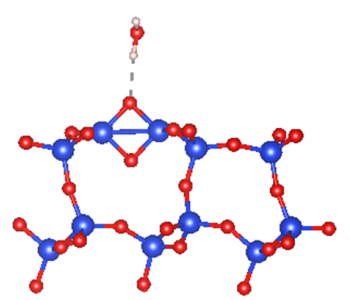

(001): $0.5 \mathrm{ML}$

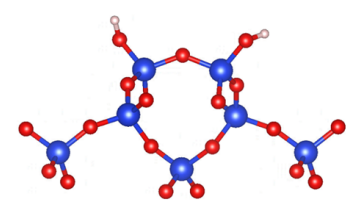

(111): $1 \mathrm{ML}$

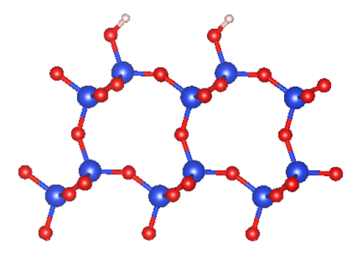

(001): $1 \mathrm{ML}$

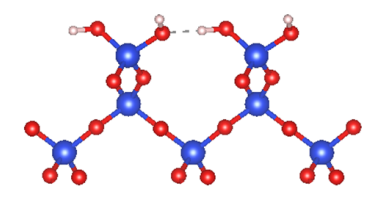

Fig. 2 Fully and partially hydroxylated surfaces of $\beta$-cristobalite. Top: molecularly (left) and dissociatively (right) adsorbed $1 \mathrm{ML}$ of water on the (111) surface. Bottom: dissociative adsorption of $0.5 \mathrm{ML}$ (left) and 1 $\mathrm{ML}$ (right) of water on the (001) surface. $\mathrm{Si}, \mathrm{O}$, and $\mathrm{H}$ atoms are represented by large blue, medium red, and small white balls, respectively.

optimizations, starting from various interface registries between the two lattices.

The interface strength is estimated from the separation energy $\mathrm{E}^{\text {sep }}=\left(\mathrm{E}^{\mathrm{a}-\text { slab }}+\mathrm{E}^{\mathrm{Zn}}-\mathrm{E}^{\mathrm{Zn} / \mathrm{a}-\text { slab }}\right) / \mathrm{S}$, where $\mathrm{E}^{\mathrm{Zn} / \mathrm{a}-\text { slab }}, \mathrm{E}^{\mathrm{a}-\text { slab }}$, and $\mathrm{E}^{\mathrm{Zn}}$ are the total energies of the $\mathrm{Zn} / \mathrm{SiO}_{2}\left(\mathrm{H}_{\mathrm{n}} \mathrm{O}_{\mathrm{m}}\right)$ heterostructure and of the isolated hydroxylated silica and $\mathrm{Zn}$ slabs with the same in-plane lattice parameters. The interface stability is estimated from the interface energy $E^{\text {int }}=\sigma_{\mathrm{SiO}_{2}\left(\mathrm{H}_{\mathrm{n}} \mathrm{O}_{\mathrm{m}}\right)}+\sigma_{\mathrm{Zn}}-\mathrm{E}^{\text {sep }}$.

\section{Results}

We start with a brief description of the models of hydroxylated $\beta$-cristobalite surfaces used in the present study. Thereafter, we report results on zinc interaction with fully and partially hydroxylated surfaces and on the effect of interface dehydrogenation on the adhesion strength.

\subsection{Hydroxylated $\beta$-cristobalite surfaces}

Both molecularly and dissociatively adsorbed water can be stabilized on the stoichiometric surfaces of the $\beta$-cristobalite, as exemplified in the case of the (111)-oriented surface, Fig. 2. While water molecules interact only weakly with intact surface siloxane rings $\left(\mathrm{E}_{\mathrm{ads}}=0.25 \mathrm{eV} / \mathrm{H}_{2} \mathrm{O}\right)$, ring breaking leads to a much more stable dissociative adsorption configuration $\left(\mathrm{E}_{\text {ads }}=1.69\right.$ $\mathrm{eV} / \mathrm{H}_{2} \mathrm{O}$ ). The large stability difference between the two configurations is consistent with the known hydroxylated character of silica surfaces under realistic thermodynamic conditions. In the following we will systematically focus on dissociatively adsorbed water and, in addition to the fully hydroxylated (111) surface, we will consider also fully and partially hydroxylated (001)-oriented surfaces, Fig. 2.

While the fully hydroxylated (111) surface [single water molecule per (111) surface unit cell] is characterized by isolated silanols, the fully hydroxylated (001) one [two water molecules 


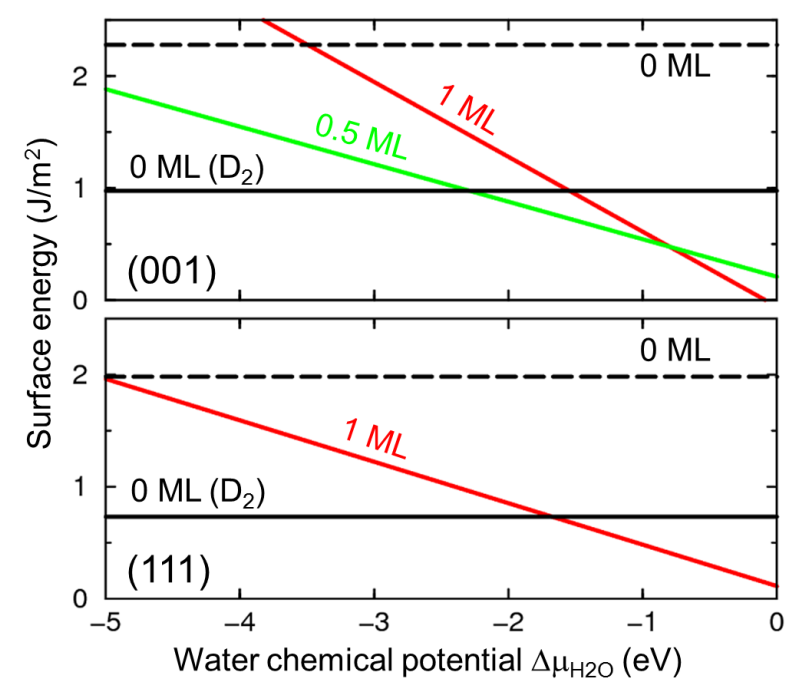

Fig. 3 Surface energies $\left(\mathrm{J} / \mathrm{m}^{2}\right)$ of hydroxylated surfaces of $\beta$-cristobalite, as a function of water chemical potential $\Delta \mu_{H_{2} O}(\mathrm{eV})$. Results for (001) and (111) terminations are given in top and bottom panels, respectively. The surface energies of bare surfaces $(0 \mathrm{ML})$ with both intact $\left(D_{2}\right)$ and broken (dashed line) surface siloxane rings are recalled.

per (001) surface unit cell] exposes geminal silanols which form H-bonded chains along the [100] direction. Our lowest energy configurations correspond to the most stable structures in Refs. ${ }^{38}$ and $^{41}$. In the case of a partial hydroxylation of the (001) surface [one water molecule per (001) surface unit cell], our lowest energy configuration is characterized by a five-member Si-O ring similar to those reported in Refs. ${ }^{35,37,41}$. The stability pattern of hydroxylated terminations is similar for both surface orientations, Fig. 3. Bare, siloxane-terminated surfaces (0 ML) are thermodynamically favored only under considerably water-lean environments, $\Delta \mu_{\mathrm{H}_{2} \mathrm{O}}<-2.2 \mathrm{eV}$ and $-1.7 \mathrm{eV}$ for (001) and (111) surfaces, respectively. Under moderate and rich water conditions partial and complete hydroxylation occurs.

While the density of surface hydroxyls at the fully hydroxylated (001) surface is relatively high, $\sim 8 \mathrm{OH} / \mathrm{nm}^{2}$, at the fully hydroxylated (111) and at the partially hydroxylated (001) surfaces it is equal to $\sim 4-5 \mathrm{OH} / \mathrm{nm}^{2}$, close to that measured experimentally on amorphous silica under standard temperature and pressure conditions, $\sim 4.9 \pm 0.6 \mathrm{OH} / \mathrm{nm}^{2}$. ${ }^{54}$. In the following we will systematically consider the (111): 1ML (111), (001): 1ML, and (001): 0.5 ML configurations described above, which correspond to hydroxyl densities of $4.6,8.4$, and $4.2 \mathrm{OH} / \mathrm{nm}^{2}$, respectively, and are representative for various realistic types and densities of surface silanols.

\subsection{Zinc interaction with hydroxylated $\beta$-cristobalite sur- faces}

The characteristics of zinc interaction with the hydroxylated surfaces of $\beta$-cristobalite are summarized in Fig. 4 and Tab. 1. We find that, regardless of the surface orientation, zinc adhesion at fully and partially hydroxylated surfaces is very weak,

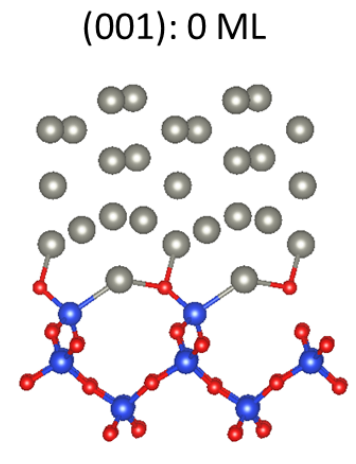

(001): $0.5 \mathrm{ML}$
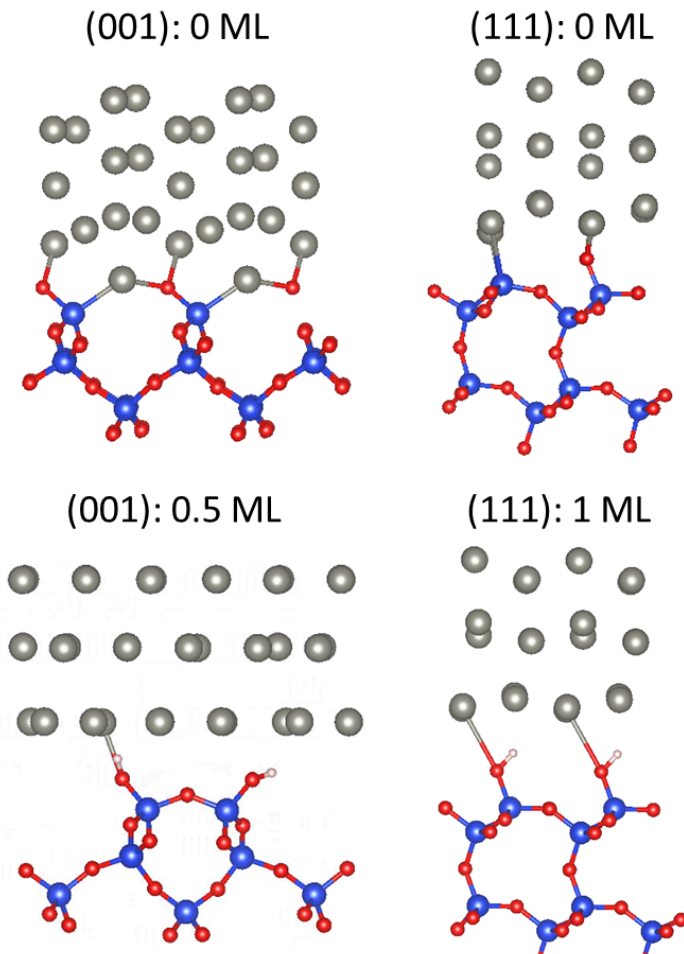

(111): $1 \mathrm{ML}$

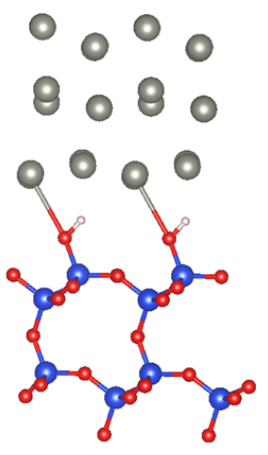

(001): $1 \mathrm{ML}$

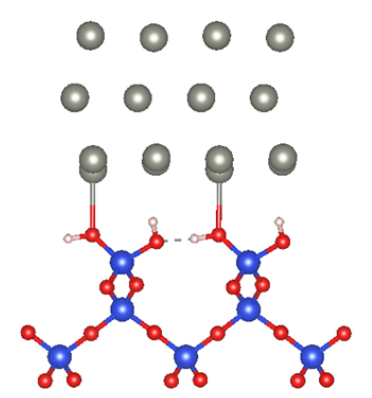

Fig. 4 Zinc deposits on dry (0 ML), partially $(0.5 \mathrm{ML})$ and fully $(1 \mathrm{ML})$ hydroxylated (001) (left) and (111) (right) surfaces of the $\beta$-cristobalite. The density $d$ of interface silanols increases from top to bottom, with $\mathrm{d}_{\mathrm{OH}}^{001}(0.5 \mathrm{ML}) \sim \mathrm{d}_{\mathrm{OH}}^{111}(1 \mathrm{ML})$. Si, $\mathrm{Zn}, \mathrm{O}$, and $\mathrm{H}$ atoms are represented by large blue and grey, medium red, and small white balls, respectively. 


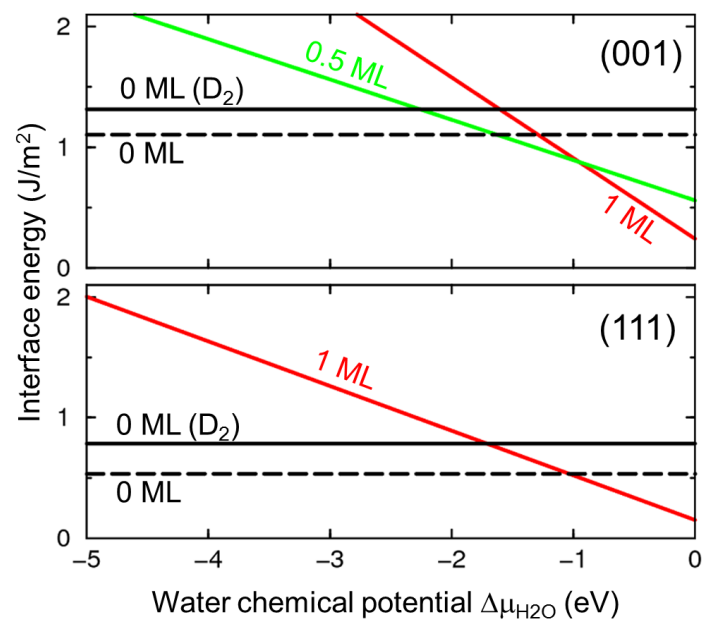

Fig. 5 Interface energies $\left(\mathrm{J} / \mathrm{m}^{2}\right)$ of dry and hydroxylated zinc/ $\beta$-cristobalite interfaces, as a function of water chemical potential $\Delta \mu_{H_{2} O} \mathrm{O}(\mathrm{eV})$. Results for the (001) and (111) interfaces are given in the top and bottom panels, respectively.

Tab. 1, with no strong Zn-O or Zn-Si bonds, no noticeable interface charge transfer, and no spontaneous modification of the network of H-bonds in the hydroxylation layer. We recall that an equally weak interface interaction, $\mathrm{E}_{\mathrm{sep}} \sim 0.3-0.5 \mathrm{~J} / \mathrm{m}^{2}$, is characteristic of the contact between zinc and surface siloxane rings [0 $\left.\mathrm{ML}\left(\mathrm{D}_{2}\right)\right]$ in the absence of hydroxylation, as described in Ref. ${ }^{27}$. Conversely, interfaces with broken siloxanes (0 ML), Fig. 4, produce a much larger $\mathrm{E}_{\text {sep }} \sim 1.8-2.0 \mathrm{~J} / \mathrm{m}^{2}$, due to strong interfacial iono-covalent $\mathrm{Zn}-\mathrm{O}$ bonds.

Table 1 Separation energies $\mathrm{E}_{\text {sep }}\left(\mathrm{J} / \mathrm{m}^{2}\right)$ at hydroxylated and dry zinc/silica interfaces.

$\begin{array}{cccc} & 1 \mathrm{ML} & 0.5 \mathrm{ML} & 0 \mathrm{ML}\left(\mathrm{D}_{2}\right) / 0 \mathrm{ML} \\ (001) & 0.34 & 0.28 & 0.30 / 1.81 \\ (111) & 0.51 & - & 0.50 / 2.00\end{array}$

The adhesion strength contributes to the relative stability of the hydroxylated interfaces, Fig. 5. On the one hand, since the zinc-silica interaction is equally weak at the hydroxylated (1.0 $\mathrm{ML}, 0.5 \mathrm{ML}$ ) and at the dry interfaces with intact siloxane rings [0 ML $\left(D_{2}\right)$ ], the relative stability pattern of these configurations is practically unaltered with respect to that of the corresponding surfaces, Fig. 3, and the transitions take place under virtually the same water conditions $\Delta \mu_{\mathrm{H}_{2} \mathrm{O}}$.

On the other hand, as described in Ref. ${ }^{27}$, the zinc deposits stabilize interfaces with broken siloxane rings ( $0 \mathrm{ML}$ ) with respect to those with the intact ones $\left[0 \mathrm{ML}\left(\mathrm{D}_{2}\right)\right]$. These interfaces become the most thermodynamically stable under a wide range of waterlean and water-moderate conditions, $\Delta \mu_{\mathrm{H}_{2} \mathrm{O}}<-1.3 \mathrm{eV}$ and $-1.0 \mathrm{eV}$ for (001) and (111)-oriented interfaces, respectively. However, despite their enhanced thermodynamic stability, these configurations may not be easy to obtain by zinc deposition on bare silica surfaces, due to the large energy barrier which has to be overcome in order to break the interface siloxanes. ${ }^{27}$

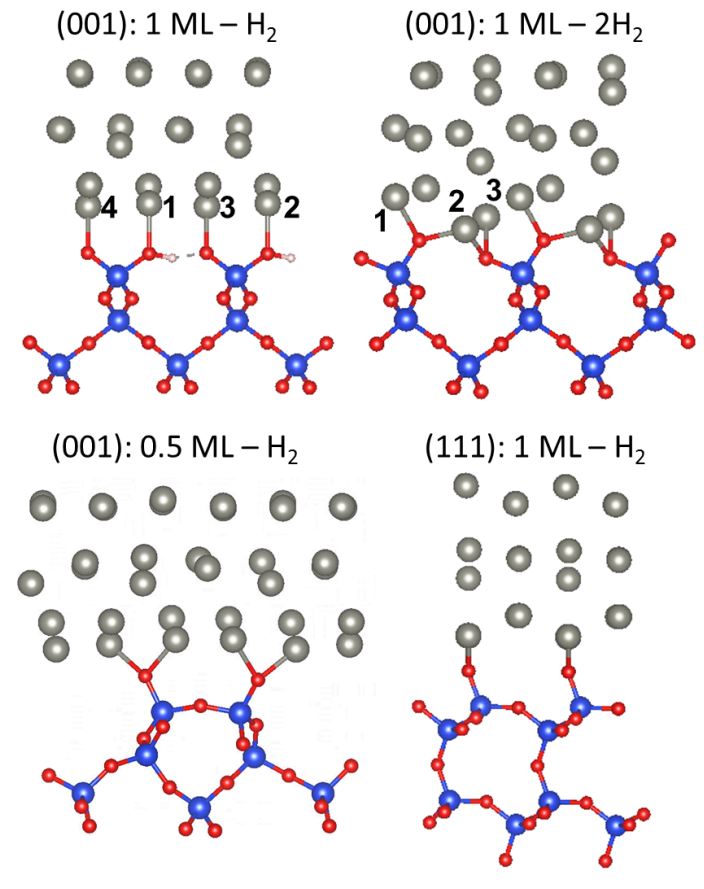

Fig. 6 Relaxed structure of the partially and fully dehydrogenated zinc/silica interfaces. Top: fully hydroxylated (001) interfaces after desorption of one (left) and two (right) hydrogen molecules. Bottom: partially hydroxylated (001) (left) and fully hydroxylated (111) (right) interfaces after desorption of one hydrogen molecule. $\mathrm{Si}, \mathrm{Zn}, \mathrm{O}$, and $\mathrm{H}$ atoms are represented by large blue and grey, medium red, and small white balls, respectively.

To summarize, the enhancement of zinc/silica interface strength is directly correlated to the presence of interfacial $\mathrm{Zn}$ $O$ bonds between under-coordinated surface anions and the zinc deposit. When present, surface silanols impede the formation of such bonds and thus produce a passivating effect which is detrimental to the zinc-silica interaction. In this context, dehydrogenation of the hydroxylated zinc/silica interfaces appears as a potentially promising route for an improvement of their adhesion.

\subsection{Zinc/ $\beta$-cristobalite interaction at dehydrogenated inter- faces}

Since a fully valid description of the kinetics of dehydrogenation would require to account for hydrogen dynamics beyond the Born-Oppenheimer separation used in the present study, in the following we focus on the thermodynamics and adhesion characteristics of hydrogen-lean zinc/silica interfaces. Figure 6 shows the optimized atomic configurations obtained by a dehydrogenation of fully and partially hydroxylated (001) and (111) interfaces. Table 2 summarizes their separation energies and the charges of zinc atoms involved in the interfacial $\mathrm{Zn}-\mathrm{O}$ bonds.

We find that dehydrogenation induces a substantial increase of the adhesion strength, regardless of the interface orientation and hydroxylation state. Indeed, with respect to small $\mathrm{E}_{\mathrm{sep}} \sim 0.3$ $0.5 \mathrm{~J} / \mathrm{m}^{2}$ at the fully and partially hydroxylated interfaces (1 ML, $0.5 \mathrm{ML}$ ), the separation energies increase up to as much as 3.5 - $4.0 \mathrm{~J} / \mathrm{m}^{2}$ at hydrogen-free interfaces [(001): $1 \mathrm{ML}-2 \mathrm{H}_{2}$ and 
Table 2 Separation energies $E_{\text {sep }}\left(J / \mathrm{m}^{2}\right)$ and charges of $Z n$ atoms involved in $\mathrm{Zn}-\mathrm{O}$ bonds (ordered according to labels in Fig. 6) at the $(001)$ and (111) zinc/ $\beta$-cristobalite interfaces with various degrees of dehydrogenation.

$\begin{array}{lrc} & \mathrm{E}_{\text {sep }} & \mathrm{QZn}_{\mathrm{Zn}} \\ (001) & & 0.17(\times 2) \\ 1 \mathrm{ML} & 0.34 & 0.31(\times 2), 0.38(\times 2) \\ 1 \mathrm{ML}-\mathrm{H}_{2} & 1.97 & 0.30(\times 2), 0.67(\times 2), 0.34(\times 2)\end{array}$

(001)

$\begin{array}{llr}0.5 \mathrm{ML} & 0.28 & 0.14,0.09 \\ 0.5 \mathrm{ML}-\mathrm{H}_{2} & 2.68 & 0.33(\times 2), 0.38(\times \\ & & \\ (111) & & 0.12(\times 2) \\ 1 \mathrm{ML} & 0.51 & 0.34(\times 4)\end{array}$

(111): $1 \mathrm{ML}-\mathrm{H}_{2}$ ]. Partial dehydrogenation [(001): $1 \mathrm{ML}-\mathrm{H}_{2}$ ] or dehydrogenation of the partially hydroxylated interface [(001): $0.5 \mathrm{ML}-\mathrm{H}_{2}$ ] produces intermediate values of about $2.0-2.7 \mathrm{~J} / \mathrm{m}^{2}$.

The reinforcement of adhesion is principally driven by the formation of strong iono-covalent $\mathrm{Zn}-\mathrm{O}$ bonds, involving undercoordinated surface anions, remnant of surface $\mathrm{OH}$ groups. Indeed, the trend of the calculated adhesion energy can be linked to the number (per unit cell) of such excess anions: 0 (1 ML), 1 [(001): $1 \mathrm{ML}-\mathrm{H}_{2},(001): 0.5-\mathrm{H}_{2}$, and (111): $\left.1 \mathrm{ML}-\mathrm{H}_{2}\right]$ and 2 [(001): $1 \mathrm{ML}-2 \mathrm{H}_{2}$ ]. However, it is clear that the number of bonds and the coordination of the involved atoms also matter, as illustrated by, e.g., quite different adhesion characteristics of the three configurations with a single excess anion per surface unit cell.

The presence of excess anions drives a significant electron transfer from the metal deposit towards the oxide substrate, which results in a partial ionization of the zinc atoms involved in the $\mathrm{Zn}-\mathrm{O}$ bonds and enables the anions to recover their 2- oxidation state. Indeed, this electron transfer of about $0.3-0.4 e / \mathrm{Zn}$ is approximately twice larger than that along the bonds between $\mathrm{Zn}$ and surface siloxane rings (0.13-0.18 $\mathrm{e} / \mathrm{Zn}$ ), or between $\mathrm{Zn}$ and surface $\mathrm{OH}$ groups $(0.12-0.17 \mathrm{e} / \mathrm{Zn})$. Moreover, the overall charge of the zinc deposit scales with the number of excess anions at the interface: $0.24-0.34 e$ for 1 ML coverage (no excess anions), 1.36-1.38 $e$ for configurations with a single excess anion per unit cell, and $2.62 e$ for the configuration (001): $1 \mathrm{ML}-2 \mathrm{H}_{2}$ with two excess anions per unit cell. This clearly shows that the driving force of adhesion improvement is the interface non-stoichiometry which results from the dehydrogenation process.

Figure 7 reports the stability diagrams of the (001)and (111) zinc/ $\beta$-cristobalite interfaces of various degrees of hydroxylation and dehydrogenation. Only few among the configurations that we have considered are thermodynamically stable. We first note that both (001) and (111) diagrams are dominated by H-lean configurations. Indeed, interfacial hydrogen atoms are stable only under strongly H-rich environments $\left(\delta \mu_{H}>-0.5 \mathrm{eV}\right)$. This is clearly in contrast to what happens in the absence of zinc (red in Fig. 7), where surface hydroxyls on oxygen-rich configurations

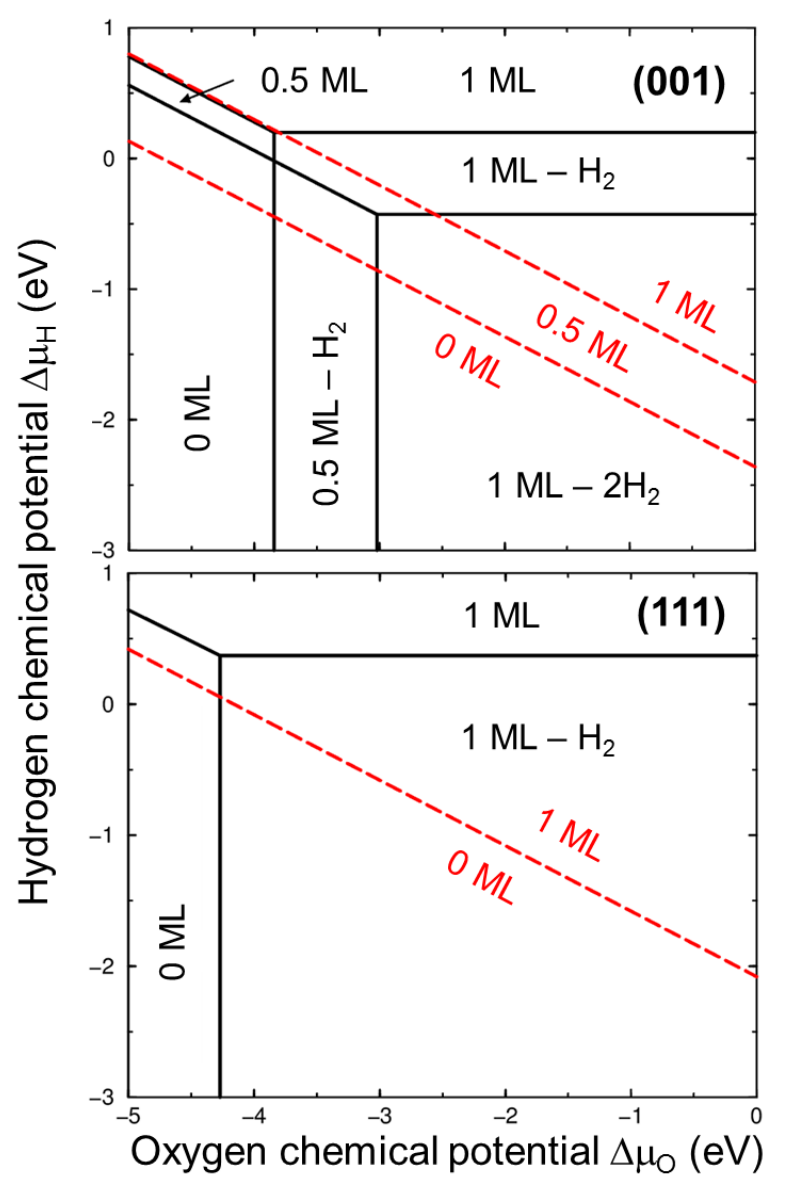

Fig. 7 Stable zinc/ $\beta$-cristobalite (001) and (111) interface configurations, as a function of oxygen and hydrogen chemical potentials $\Delta \mu_{O}$ and $\Delta \mu_{H}(\mathrm{eV})$. As a reference, red labels and red dashed lines recall the corresponding configurations in the absence of zinc. 
remain stable even under relatively H-lean conditions $\left(\delta \mu_{H} \sim\right.$ $2.0 \mathrm{eV}$ ). This comparison reveals a thermodynamic bias for an exchange between surface hydrogen and zinc atoms present under a wide span of oxygen-moderate and -rich environments. We recall that a similar trend has already been reported for $\mathrm{Zn}$ adsorbates at the hydroxylated $\alpha$-alumina terminations, ${ }^{32}$ for which the activated character of the hydrogen-zinc exchange has been explicitly demonstrated by both experiment and first principles calculations. ${ }^{27}$

More importantly, all H-lean interface configurations present in the stability diagram Fig. 7, are characterized by satisfactory or even excellent adhesion characteristics. This applies to both stoichiometric (0 ML) and oxygen-lean interfaces (not considered in the present study, see ref. ${ }^{27}$ ), stable for $\Delta \mu_{O} \leq-4 \mathrm{eV}$ ), and also to the oxygen-rich interfaces ( $\left.1 \mathrm{ML}-\mathrm{nH}_{2}\right)$, issued from a full dehydrogenation of the initial surface hydroxylation layer, stable under the remaining large span of oxygen-moderate and oxygenrich environments.

In summary, we have shown that a dehydrogenation of hydroxylated zinc/silica interfaces in all cases results in a substantial adhesion enhancement. It is associated with the formation of iono-covalent interfacial $\mathrm{Zn}-\mathrm{O}$ bonds and with significant electron transfers towards the oxide substrate. We assign this favorable effect to the presence of an excess of under-coordinated interfacial anions, remnant of surface hydroxyls groups. Their density has a clear impact on the interfacial strength and the overall positive charge of the zinc deposit. Interestingly, we find that the dehydrogenated interface configurations with the largest density of such under-coordinated interface anions are the most thermodynamically stable over a large range of realistic oxygen and hydrogen conditions. These results consistently show that surface prehydroxylation, followed by hydrogen desorption can be a promising route towards the formation of oxygen-rich interfaces with particularly interesting adhesion characteristics.

\section{Discussion}

The computational results show that separation energies at the fully dehydrogenated interfaces are particularly large (3.4 - 4.0 $\mathrm{J} / \mathrm{m}^{2}$ ), which suggests an excellent wetting of silica by zinc and makes these configurations interesting for applications in zinc coatings. Moreover, we find that the oxygen-rich character of these interfaces is responsible for a substantial interface charge transfer, which leads to a partial ionization of the interfacial zinc atoms. We recall that the corresponding oxygen-rich terminations of the $\beta$-cristobalite are polar, ${ }^{27,55}$ and thus a compensating charge [four and two holes per (100) and (111) surface unit cells, respectively] is necessary to ensure their electrostatic stability. Partial ionization of the interfacial zinc atoms can thus be seen as a screening of surface polarity by the metal deposit.

In the following we estimate to what extent the interfacial charge transfer and the partial zinc ionization may impact the bonding within the zinc deposit itself. To this goal we have focused on the (001): $1 \mathrm{ML}-2 \mathrm{H}_{2}$ and (111): $1 \mathrm{ML}-\mathrm{H}_{2}$ interfaces and have evaluated separation energies for a series of possible cuts within the zinc deposit, characterized by various fractions $f$ of the interfacial zinc atomic layer left on the oxide substrate after the separation. We have considered $f_{(001)}=1 / 4,1 / 2$, and 1 , and $f_{(111)}=1 / 8,1 / 2$, and 1 , for the (001) and (111) interfaces, which corresponds to 2,4 , and 8 and to 1,4 , and 8 remaining zinc atoms per unit cell, respectively. These configurations are thus complementary to those discussed in the preceding section, where no zinc was left on the silica surface upon separation ( $f$ $=0$ ) and to those for which the zinc deposit is cut far from the interface $(f=\infty)$.

Table 3 Separation energies $\mathrm{E}_{\text {sep }}\left(\mathrm{J} / \mathrm{m}^{2}\right)$ obtained for various cuts of the (001): $1 \mathrm{ML}-2 \mathrm{H}_{2}$ and (111): $1 \mathrm{ML}-\mathrm{H}_{2}$ interfaces, characterized by a different fraction $f$ of the interfacial zinc layer left on the oxide substrate. As a reference, corresponding $\mathrm{E}_{\mathrm{sep}}$ obtained for cuts far from the interface with silica $(f=\infty)$ are recalled.

$\begin{array}{llll}f_{(001)} & \mathrm{E}_{\text {sep }} & f_{(111)} & \mathrm{E}_{\text {sep }} \\ 0 & 4.03 & 0 & 3.41 \\ 1 / 4 & 1.47 & 1 / 8 & 1.03 \\ 1 / 2 & 1.14 & 1 / 2 & 1.89 \\ 1 & 1.46 & 1 & 1.42 \\ \infty & 1.28 & \infty & 1.10\end{array}$

The results summarized in Tab. 3 show that, regardless of the interface orientation, the behavior of $\mathrm{E}_{\mathrm{sep}}$ is far from being monotonic and that the strong interaction found at the very zinc/silica interface $(f=0)$ is accompanied by a considerable decrease of bonding in its direct vicinity ( $f=1 / 2$ and $1 / 8$ for (001) and (111) interfaces, respectively). The small separation energies obtained in these two cases are even slightly smaller than the corresponding reference strengths in the zinc deposit itself, $f=\infty$. While the differences are small $\left(\Delta \mathrm{E}_{\mathrm{sep}} \sim 0.1 \mathrm{~J} / \mathrm{m}^{2}\right)$ and likely beyond the precision of the present model calculations, the decrease of $E_{\text {sep }}$ in the interface vicinity has a relatively well defined physical origin.

Indeed, in these two configurations, the number of $\mathrm{Zn}$ atoms left on the surface (4 and 1 per (001) and (111) surface unit cell, respectively) can be linked to the number of excess anions ( 2 and 1, respectively). These surface configurations can be seen as stoichiometric silica decorated with $\mathrm{Zn}_{4} \mathrm{O}_{2}$ and $\mathrm{ZnO}$ species, respectively, which are charge neutral, without $(\mathrm{ZnO})$ or with a metal excess $\left(\mathrm{Zn}_{4} \mathrm{O}_{2}\right)$. As a consequence, contrary to the bare oxygen-rich terminations $\left(\sigma_{\mathrm{SiO}_{2}+\mathrm{O}}\right)$, their surface energies $\sigma_{\mathrm{SiO}_{2}}+\mathrm{Zn}_{\mathrm{n}} \mathrm{O}$ involve no extra cost due to polarity compensation $\left(\sigma_{\mathrm{SiO}_{2}+\mathrm{Zn}_{\mathrm{n}} \mathrm{O}}<<\sigma_{\mathrm{SiO}_{2}+\mathrm{O}}\right)$ and, for a given interface configuration of energy $E^{\text {int }}$, they produce a much smaller adhesion $E^{\text {sep }}$ $=\sigma_{\mathrm{SiO}_{2}+\mathrm{Zn}_{\mathrm{n}} \mathrm{O}}+\sigma_{\mathrm{Zn}}-\mathrm{E}^{\mathrm{int}}<<\sigma_{\mathrm{SiO}_{2}+\mathrm{O}}+\sigma_{\mathrm{Zn}}-\mathrm{E}^{\mathrm{int}}$. We note that the zinc excess in the case of the (001)-orientated surface does not alter this argument, because the energy cost of a partial hole delocalization over the additional $\mathrm{Zn}$ atoms is compensated by the energy gain of additional $\mathrm{Zn}-\mathrm{O}$ bonds. This is not the case on the (111) surface due to the isolated character of its surface silanols.

To summarize, despite particularly large separation energies at the very zinc/oxide interface $\left(3.4-4.0 \mathrm{~J} / \mathrm{m}^{2}\right)$ and satisfactory separation energies in the interface vicinity (minimal $\mathrm{E}_{\mathrm{sep}}=$ 1.03-1.14 J/ $\mathrm{m}^{2}$ larger than at interfaces containing intact siloxanes : $0.30-0.50 \mathrm{~J} / \mathrm{m}^{2}$ ), these results show that the oxygen-rich contacts may not provide an optimal wetting behavior. Indeed, 
the predicted effect of decohesion in the zinc deposit (minimal $\left.\mathrm{E}_{\text {sep }}<E_{\text {sep }}\left(f_{\infty}\right)\right)$ suggests that the oxide surfaces decorated by oxidized zinc species interact weakly with the remaining metallic part of the zinc deposit. Let us stress, however, that the calculated decohesion effect is small and likely inferior to the precision of the present approach, due to both an approximate treatment of exchange and correlations and to the structural constraints imposed by the supercell geometry. Alternative routes for adhesion improvement of zinc/silica interfaces, based, e.g., on interfacial buffers made of more reactive elements ${ }^{56-58}$, could be envisioned and are presently under study in our group.

\section{Conclusions}

We have used $\mathrm{ab}$ initio modeling to analyze the interaction of zinc with hydroxylated silica, represented by fully or partially hydroxylated (001) and (111) surfaces of $\beta$-cristobalite.

We find that, regardless of the surface orientation and of the degree of hydroxylation (type of surface siloxanes and the presence of H-bonds), zinc adheres very weakly to hydroxylated silica surfaces due to the passivating effect of surface silanols. According to our results, zinc interaction with the hydroxylated surfaces is essentially as weak as that with the bare siloxane-terminated ones.

Interestingly, we find that dehydrogenation dramatically improves the interface strength. This is principally due to the formation of strong iono-covalent bonds between the zinc deposit and the under-coordinated excess interfacial anions, remnant of the initial hydroxylation layer. Indeed, the density of the latter has a clear impact on the interfacial charge transfer and on the strength of the resulting dehydrogenated interfaces. Moreover, we find that such dehydrogenated interfaces are the most thermodynamically stable over a large range of realistic oxygen and hydrogen conditions. However, a weakening of the zinc-zinc interaction in the direct interface vicinity, induced by an interface charge transfer and a partial oxidation of the zinc atoms in contact with the oxide, remains possible.

This fundamental analysis of the microscopic mechanisms responsible for the interaction strength at zinc/silica interfaces under a large variety of thermodynamic conditions provides several useful guidelines for possible adhesion improvement scenarios. In particular, our results consistently point out that surface prehydroxylation followed by hydrogen desorption may provide a route for the formation of oxygen-rich interfaces with interesting adhesion characteristics.

\section{Acknowledgments}

The authors are grateful to Jacques Jupille, Rémi Lazzari, Lucie Gaouyat and Daniel Chaleix for many fruitful discussions. H.L. T. Le acknowledges a post-doctoral grant from ArcelorMittal Maizières Research. This work was supported by HPC resources from GENCI-IDRIS (Grant 2017-A0010906855).

\section{References}

1 A. R. Marder, Prog. Mater. Sci., 2000, 45, 191-271.

2 H.-T. Jiang, W. Ding, D. Tang and W. Huang, J. Iron and Steel Research, 2012, 19, 29-36.
3 Advanced high strength sheet steels, ed. N. Fonstein, Springer Int. Publishing, Switzerland, 1st edn., 2015.

4 B. Hu, H. Luo, F. Yang and H. Dong, J. Mater. Sci. Technol., 2017, 33, 1457-1464.

5 Q. Tonizzo, A.-F. Gourgues-Lorenzon, M. Maziére, A. Perlade and I. Zuazo, Mater. Sci. Eng. A, 2017, 706, 217-226.

6 J. Emo, P. Maugis and A. Perlade, Comput. Mater. Sci., 2016, 125, 206-217.

7 W. Wang, M. Li, C. He, X. Wei, D. Wang and H. Dub, Materials and Design, 2013, 47, 510-521.

8 A. Mertens, E. M. Bellhouse and J. R. McDermid, Materials Science \& Engineering A, 2014, 608, 249-257.

9 P. Drillet, Z. Zermout, D. Bouleau, J.-M. Mataigne and S. Claessens, Rev. Metall.-Cah. Inf. Tech., 2004, 10, 831-837.

10 C. Pesci, D. Chaleix, E. Silberberg and B. Chatelain, Jet vapor deposition: coating steels of the future, Paper presented at SCT2017 - 5th International Conference on Steels in Cars and Trucks, Amsterdam-Schiphol, The Netherlands, 2017.

11 C. Pesci, L. Diez, D. Chaleix, B. Chatelain and E. Silberberg, Jet vapor deposition: coating steels of the future, Paper presented at Galvatech 2017 - 11th International Conference on Zinc and Zinc Alloy Coated Steel Sheet, Tokyo, Japan, 2017.

12 C. T. Campbell, Surface Science Reports, 1997, 27, 1-111.

13 Q. Fu and T. Wagner, Surface Science Reports, 2007, 62, 431498.

14 G. Bordier and C. Noguera, Phys. Rev. B, 1991, 44, 63616371.

15 J. Goniakowski and C. Noguera, Interface Science, 2004, 12, 93-103.

16 J. Goniakowski, C. Mottet and C. Noguera, physica status solidi (b), 2006, 243, 2516-2532.

17 P. Ugliengo, M. Sodupe, F. Musso, I. J. Bush, R. Orlando and R. Dovesi, Adv. Mat., 2008, 20, 4579-4583.

18 F. Tielens, C. Gervais, J. F. Lambert, F. Mauri and D. Costa, Chem. Mater., 2008, 20, 3336-3344.

19 C. S. Ewing, S. Bhavsar, G. Veser, J. J. McCarthy and J. K. Johnson, Langmuir, 2014, 30, 5133-5141.

20 A. Comas-Vives, Phys. Chem. Chem. Phys., 2016, 18, 74757482 .

21 K. Nagao, J. B. Neaton and N. W. Ashcroft, Phys. Rev. B, 2003, 68, 125403.

22 A. C. Ngandjong, C. Mottet and J. Puibasset, J. Phys. Chem. C, 2017, 121, 3615-3622.

23 E. A. A. Jarvis and E. A. Carter, J. Am. Ceram. Soc., 2003, 86, 373-386.

24 B. Magyari-Kope, S. Park, L. Colombo, Y. Nishi and K. Cho, J. Appl. Phys., 2009, 105, 013711.

25 N. I. Vakula, G. M. Kuramshina and Y. A. Pentin, Russ. J. Phys. Chem. A, 2013, 87, 296-302.

26 P. N. Plessow, R. S. Sanchez-Carrera, L. Li, M. Rieger, S. Sauer, A. Schaefer and F. Abild-Pedersen, J. Phys. Chem. C, 2016, 120, 10340-10350.

27 H.-L. T. Le, J. Goniakowski, C. Noguera, A. Koltsov and J.-M. Mataigne, Phys. Chem. Chem. Phys., 2018, 20, 6542-6263. 
28 R. Lazzari and J. Jupille, Phys. Rev. B, 2005, 71, 045409.

29 S. A. Chambers, T. Droubay, D. R. Jennison and T. R. Mattsson, Science, 2002, 297, 827-831.

30 J. A. Kelber, C. Niu, K. Shepherd, D. R. Jennison and A. Bogicevic, Surf. Sci., 2000, 446, 76-88.

31 C. Niu, K. Shepherd, D. Martini, J. Tong, J. A. Kelber, D. R. Jennison and A. Bogicevic, Surf. Sci., 2000, 465, 163-176.

32 R. Cavallotti, J. Goniakowski, R. Lazzari, J. Jupille, A. Koltsov and D. Loison, J. Phys. Chem. C, 2014, 118, 13578-13589.

33 H.-L. T. Le, R. Lazzari, J. Goniakowski, R. Cavallotti, S. Chenot, C. Noguera, J. Jupille, A. Koltsov and J.-M. Mataigne, J. Phys. Chem. C Letters, 2017, 121, 11464-11471.

34 M. V. Koudriachova, J. V. L. Beckers and S. W. de Leeuw, Comp. Mater. Sci., 2001, 20, 381-386.

35 E. Chagarov, A. A. Demkov and J. B. Adams, Phys. Rev. B, 2005, 71, 075417.

36 F. Vigné-Maeder and P. Sautet, J. Phys. Chem. B, 1997, 101, 8197-8203.

37 X. Rozanska, F. Delbecq and P. Sautet, Phys. Chem. Chem. Phys., 2010, 12, 14930-14940.

38 D. Ceresoli, M. Bernasconi, S. Iarlori, M. Parrinello and E. Tosatti, Phys. Rev. Lett., 2000, 84, 3887-3890.

39 I.-S. Chuang and G. E. Maciel, J. Phys. Chem. B, 1997, 101, 3052-3064.

40 The surface properties of silicas, ed. E. A. P. Legrand, Wiley, New York, 1st edn., 1998.

41 S. Iarlori, D. Ceresoli, M. Bernasconi, D. Donadio and M. Parrinello, J. Phys. Chem. B, 2001, 105, 8007-8013.

42 G. Kresse and J. Furthmuller, Phys. Rev. B, 1996, 54, 1116911186.

43 G. Kresse and J. Hafner, Phys. Rev. B, 1993, 47, 558-561.

44 P. E. Blöchl, Phys. Rev. B, 1994, 50, 17953-17979.

45 G. Kresse and J. Joubert, Phys. Rev. B, 1999, 59, 1758-1775.

46 M. Dion, H. Rydberg, E. Schroder, D. C. Langreth and B. I. Lundqvist, Phys. Rev. Lett., 2004, 92, 246401.

47 J. Klimes, D. R. Bowler and A. Michaelides, J. Phys.: Cond. Matt., 2010, 22, 022201.

48 J. Klimes, D. R. Bowler and A. Michaelides, Phys. Rev. B, 2011, 83, 195131.

49 R. F. W. Bader, Chem. Rev., 1991, 91, 893-928.

50 G. Henkelman, A. Arnaldsson and H. Jonsson, Comput. Mater. Sci., 2006, 36, 354-360.

51 K. Momma and F. Izumi, J. Appl. Crystallogr., 2011, 41, 12721276.

52 T. Demuth, Y. Jeanvoine, J. Hafner and J. G. Angyan, J. Phys.: Condens. Matter, 1999, 11, 3833.

53 J. Neugebauer and M. Scheffler, Phys. Rev. B, 1992, 46, 16067-16080.

54 L. T. Zhuravlev, Colloids Surf. 1, 2000, 173, 1-38.

55 J. Goniakowski, F. Finocchi and C. Noguera, Rep. Prog. Phys., 2008, 71, 016501.

56 R. Cavallotti, H.-L. T. Le, J. Goniakowski, R. Lazzari, J. Jupille, A. Koltsov and D. Loison, Phys. Chem. Chem. Phys., 2016, 18,
3032-3039.

57 H.-L. T. Le, J. Goniakowski, C. Noguera, A. Koltsov and J.-M. Mataigne, J. Phys. Chem. C, 2016, 120, 9836-9844.

58 H.-L. T. Le, J. Goniakowski, C. Noguera, A. Koltsov and J.-M. Mataigne, J. Phys. Chem. C, 2017, 121, 25143-25151. 